\section{Ein volles Haus bei den Röntgens!}

Anlässlich des Tages des offenen Denkmals am 8. September 2019 hatten sich zahlreiche Besucherinnen und Besucher im Geburtshaus von Wilhelm Conrad Röntgen in Remscheid-Lennep eingefunden, um die dortige Publikumsausstellung persönlich in Augenschein zu nehmen.

Anlässlich des diesjährigen Tages des offenen Denkmals waren viele Bürgerinnen und Bürger der Einladung gefolgt, die Publikumsausstellung „Auf Röntgens Spuren“ im Geburtshaus Röntgens zu besuchen. Die Ausstellung, die maßgeblich von der NRWStiftung und dem Landschaftsverband Rheinland mitfinanziert wurde, widmet sich ganz der Person Röntgens und seiner Lebensleistung. Sie bietet Einblicke in die Familie und zeigt Stationen seines Lebens, von seiner Geburt in der bergischen Stadt Lennep, über seine Schulzeit, sein Studium bis hin zu seinen beruflichen Stationen in Gießen, Würzburg und München. Besonderes Interesse weckte dabei die sogenannte Schatzkammer, für die das Deutsche Rönt-
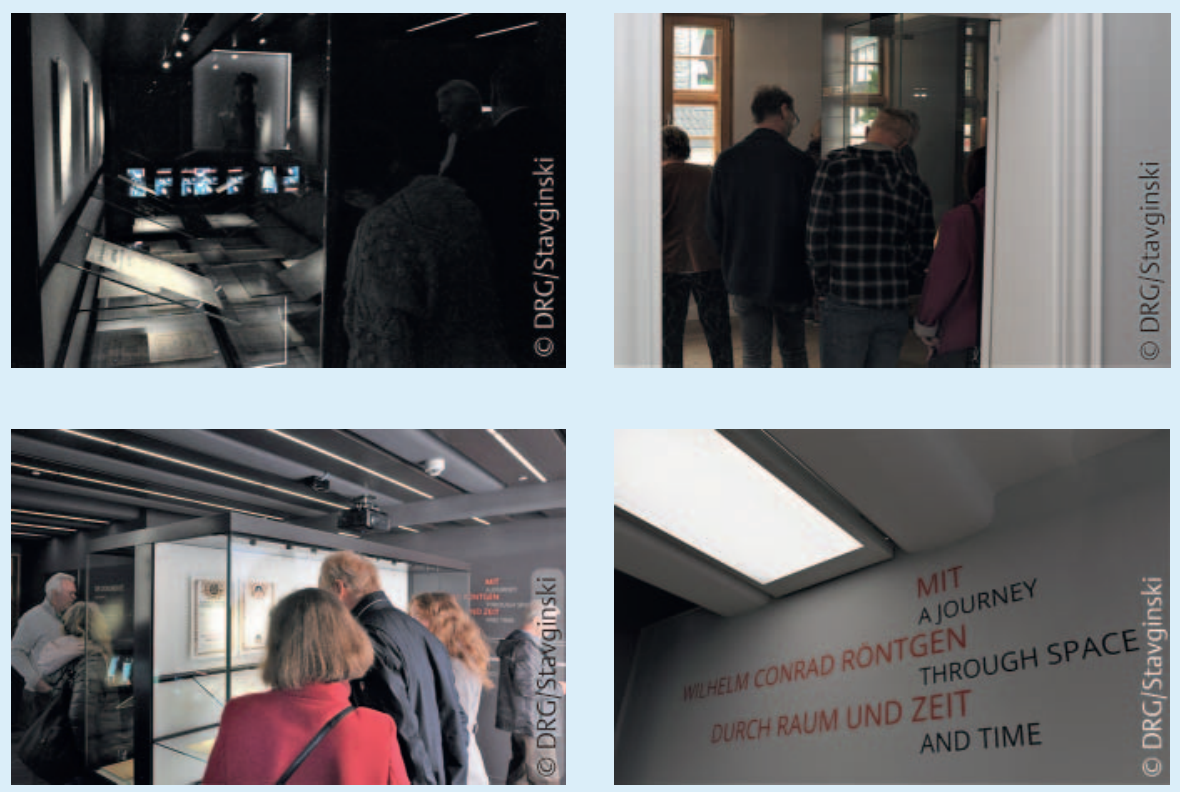

genmuseum aus seinen Archiven eine Auswahl besonderer Dokumente, Urkunden und Briefe zur Verfügung gestellt hat.

Die Besucherinnen und Besucher zeigten sich begeistert und voller Vorfreude auf die endgültige Fertigstellung und Eröffnung des Hauses am 27. März 2020 anlässlich des 175. Geburtstags von Wilhelm Conrad Röntgen. 